\title{
Changes of Anthocyanidin Content and Brown Rice Yield in Three Pigmented Rice Varieties Among Different Transplanting and Harvesting Times
}

\author{
Sang-Kuk Kim*, Jong-Hee Shin*, Dong-Kyoon Kang**, Su-Yong Kim*, and Shin-Young Park*** ${ }^{\dagger}$ \\ *Division of Crop Science, Gyeongsangbuk-do Provincial Agricultural Research \& Research Services, \\ Daegu 702-708, The Republic of Korea \\ **Division of Agriculture Environment, Gyeongsangbuk-do Provincial Agricultural \\ Research \& Research Services, Daegu 702-708, The Republic of Korea \\ ***Department of Clinical Pathology, Jeju Halla University, Jeju Special Self-Governing Province, \\ Jeju 690-708, Republic of Korea
}

\begin{abstract}
Anthocyanin pigments from three pigmented rice varieties, Hongjinju, Sintoheugmi and Josaengheugchal pigmented by black color, were quantified to evaluate effects of transplanting and harvesting time during seed development. Hongjinju, a rice variety of grains pigmented by red color, contains only two kinds of anthocyanins, delphinidin and cyanidin. Meanwhile, delphinidin, cyanidin, and pelargonidin were identified in Sintoheugmi and Josaengheugchal. Anthocyanidin contents in pigmented rice variety Hongjinju under different planting times were decreased with prolonged harvesting times. The Sintoheukmi showed that cyanidin content was the highest among analyzed pigments during seed development. Two anthocyanins (cyanidin and pelargonidin) in Josaengheugchal recorded highest contents at 20 days after heading in three transplanting times. Cyanidin content was also slightly increased with prolonged transplanting time. Total anthocyanidin contents in Honginju were always lower than that of Sintoheukmi and Josaengheukchal. In two rice varieties, Sintoheugmi and Josaengheugchal, $\mathrm{a}^{*}$ values were commonly slightly decreased by late transplanting and harvesting times. Changes of $a^{*}$ and $b^{*}$ values in waxy rice varieties, Sintoheugmi and Josaengheugchal varied more than those in Hongjinju. In Josaengheugchal, early harvesting before maturity showed lower brown rice yield and late harvesting in the each transplanting times resulted in highest brown rice yield.
\end{abstract}

Keywords : pigmented rice, anthocyanidin, transplanting time

Rice (Oryza sativa L.) is one of the most important cereal crops in the world, especially in Asian countries. Pigmented rice such as black and red rice consumptions are rapidly growing presently due to their healthy functional food ingredients in Korea. Pigmented rice or colored rice is distinguished by the rice grain having red brown or dark purple color in its covering layers. Pigments, which are located in the aleurone layer of rice grain, have been reported as a mixture of anthocyanin compounds, which belong to the family of flavonoids (Yawadio et al., 2007). For pigmented rice, the main substance of phenolic compounds has been reported as anthocyanins (Iqbal et al., 2005; Zhang et al., 2006; Yawadio et al., 2007). Anthocyanins in pigmented rice have been identified. They are cyanidin-3-glucoside and peonidin-3-glucoside (Hu et al., 2003); malvidin, pelargonidin-3, 5-diglucoside, cyanidin-3-glucoside and cyanidin-3, 5-diglucoside (Zhang et al., 2006); cyanidin-3-glucoside, pelargonidin-3-glucoside (Yawadio et al., 2007). Anthocyanins, a group of reddish or purple flavonoids, are reported to be the primary pigments in these rice varieties (Abdel-Aal \& Huel, 1999; Mazza \& Gao, 2005; Moreno et al., 2005). Anthocyanins have been recognized as health-promoting functional food ingredients due to their antioxidant activity (Nam et al., 2006; Philpott et al., 2006), anticancer (Hyun \& Chung, 2004; Zhao et al., 2004), and anti-inflammatory effects (Tsuda et al., 2002), and these functions provide synergic effects with various nutrients in vivo. At present, red rice is commonly used as a food colorant in bread, ice cream, and liquor (Yoshinaga, 1986). Anthocyanins are located in certain layers of the rice grain, which could be separated into anthocyanin-rich fractions for use as functional colorants or functional food ingredients. Although an extensive scientific literature (Francis, 2000; Mazza \& Gao, 2005) on the composition

\footnotetext{
${ }^{\dagger}$ Corresponding author: (Phone) +82-64-741-7403 (E- mail) shiny@chu.ac.kr

$<$ Received 4 September, 2012; Revised 18 October, 2012; Accepted 20 December, 2012>
} 
of anthocyanins in fruits and vegetables exists, little is known about anthocyanin composition in pigmented rice. Early studies have shown cyanidin-3-glucoside (C3G) as a major anthocyanin in black rice, but the minor ones were reported either malvidin3-glucoside (Yoon et al., 1995) or peonidin-3-glucoside (Pt3G) (Choi et al., 1994).

Recently, black rice was analyzed to contain a wide range of total anthocyanin content, with $\mathrm{C} 3 \mathrm{G}$ being the most common anthocyanin $(0 \sim 470 \mathrm{mg} / 100 \mathrm{~g})$ in most of the 10 varieties studied, whereas Pt3G (0 40 mg/100 g) was the second dominant anthocyanin (Ryu et al., 1998). Researchers have reported that the contents of the functional components of pigmented rice were significantly increased according to the level of $\mathrm{N}$-fertilizer, and normal planting conditions showed significantly higher effects than early or late plantings and the contents were different according to the planting region (Chung et al., 2003). The present study was aimed to investigate whether transplanting and harvesting times affect the different contents of pigment (delphinidin, cyanidin, and pelargonidin) components and brown rice yield in three pigmented rice varieties.

\section{MATERIAL AND METHODS}

The study was conducted to found the changes of anthocyanin pigment and pasting properties of starch in three pigmented rices with different transplanting time and harvesting times at experimental fields of Gyeongsangbuk-do Provincial Agricultural Research \& Extension Services, Daegu, Republic of Korea. The three pigmented rice varieties, Hongjinju, Sintoheugmi, and Joseongheukchal, were transplanted on June 10, 20 and 30. Planting distance was $30 \times 14 \mathrm{~cm}$ and fertilizer amount was $\mathrm{N}-\mathrm{P}_{2} \mathrm{O}_{5}-\mathrm{K}_{2} \mathrm{O}=9-4.5-5.7 \mathrm{~kg} / 10 \mathrm{a}$ and fertilizer split application was basal-tillering stage-panicle initiation $=$ 50-20-30 ratio. And in the other cultivation management, we observed rice standard culture of NICS. In order to analyze rice quality and pigment content from each variety, rice seeds were sampled 20, 30, 40, and 50 days after heading from each transplanting time.

For quantification and identification of anthcyanidin pigments, anthcyanidins were extracted from the samples by weighing $5.0 \mathrm{~g}$ of pigmented rice seeds. The flours of pigmented rice grains were transferred into $50 \mathrm{ml}$ graduated cylinder and $5 \mathrm{ml}$ of extraction solution (80/20 acetonitrile/0.3\% phosphoric acid in distilled water) was added. The samples were centrifuged for $10 \mathrm{~min}$ and added $200 \mu \mathrm{l}$ of concentrated $\mathrm{HCl}$. The samples were incubated at $150^{\circ} \mathrm{C}$ for $30 \mathrm{~min}$ and then filtered through $0.45 \mu \mathrm{m}$ filter and transferred into $2 \mathrm{ml}$ vial. The aglycons of anthocyanins were prepared by acid hydrolysis of anthocyanins isolated from pigmented rice flours. The anthocyanin mixtures $(200 \mu \mathrm{l})$ in $100 \mu \mathrm{l}$ of $2 \mathrm{~N} \mathrm{HCl}$ were hydrolyzed under an atmosphere of nitrogen for $3 \mathrm{~h}$ at $98^{\circ} \mathrm{C}$. The analysis of anthocyanins in pigmented rice seeds was carried out using a HPLC system (Waters 2487, USA) equipped with a $\mathrm{C}_{18}$ reverse phase column $(4.6 \mathrm{~mm} \times 250 \mathrm{~mm})$. The extract $(200 \mu \mathrm{l})$ was mixed with $100 \mu \mathrm{l}$ of $2 \mathrm{~N} \mathrm{HCl}$ in $40 \%$ methanol solution, and then incubated at $100^{\circ} \mathrm{C}$. Samples were taken at various time periods prior to injection. HPLC was run by isocratic elution mode using $18 \%$ solvent $\mathrm{B}(0.4 \%$ TFA in acetonitrile $)$ in solvent $\mathrm{A}(0.4 \% \mathrm{TFA}$ in distilled water $)$ at a flow rate of $1.0 \mathrm{ml} / \mathrm{min}$. The elution profile was monitored by UV-detection at $530 \mathrm{~nm}$. UV-Vis spectra of anthocyanin extract from pigmented rice seeds were obtained in buffer solutions with different $\mathrm{pH}$ values (Choung et al., 2001). Small aliquots of the extract were diluted in either $200 \mathrm{mM}$ phosphate : acetonitrile, 2:1 volume ratio, $\mathrm{pH} 1.5$ or $30 \mathrm{mM}$ borate, $100 \mathrm{mM}$ SDS, $\mathrm{pH}$ 9.0. The spectrum was recorded in the range of $300 \mathrm{~nm}$ to $700 \mathrm{~nm}$ using a UV-Vis spectrophotometer (Shimadzu, Japan).

Color of dehusked grain was determined by Hunter-Lab (Ultrascan XE, Hunter-Lab, USA). Prior to color measurements, the instrument was calibrated with light tap and white calibration tile. The colorimeter was set to an illuminant condition D65 and a $10^{\circ}$ standard observer. Each sample was put in a cuvette and replaced in to the specular port site, the color parameters ( $a, b$ and L) were then read (Lamberts et al., 2007). Fifteen replicates for each sample were determined.

\section{RESULTS AND DISCUSSION}

The chromatogram of anthocyanins from pigmented rice (var. Sintoheugmi) was shown in Figure 1. Three authentic pigments were delphinidin (peak 2), cyanidin (peak 3) and pelargonidin (peak 4). Consequently, it was only quantified three anthocyanins from pigmented rices in this study.

Three pigmented rice varieties, Hongjinju, Sintoheugmi, and Joseongheukchal as affected by different transplanting time were sampled at 20,30, 40, and 50 days after heading to determine total anthocyanin contents. Anthocyanidin contents 


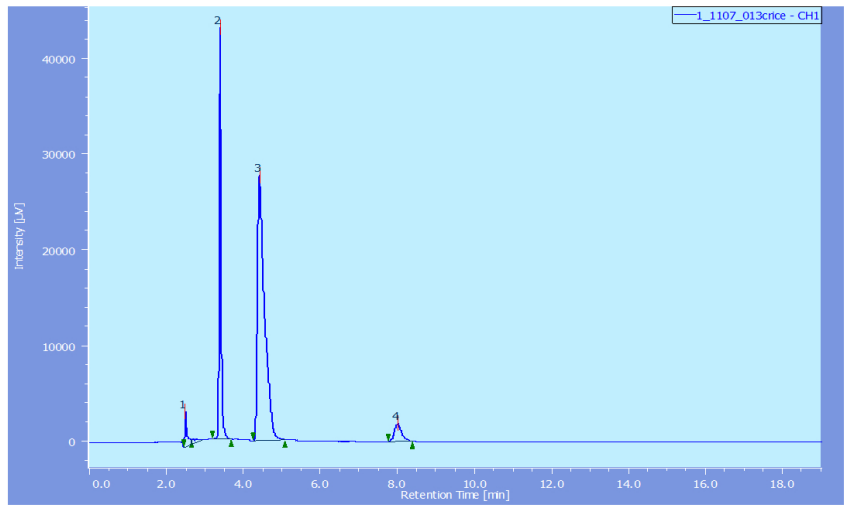

Fig. 1. Chromatogram of anthocyanin pigments separated from pigmented rice variety, Sintoheugmi. Peak 1, acetonitrile; peak 2, delphinidin; peak 3, cyanidin; peak 4, pelargonidin.
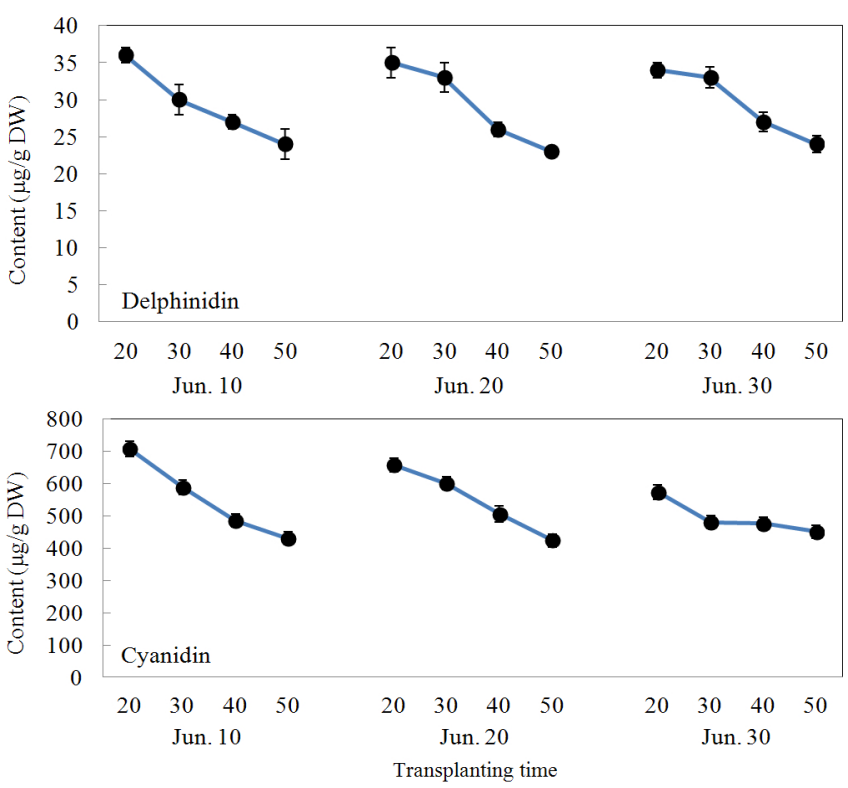

Fig. 2. Changes of delphinidin and cyanidin as affected by different transplanting and harvesting time in pigmented rice variety, Hongjinju. Vertical bar indicates means \pm SE $(n=3)$.

in Hongjinju under different planting times were decreased with prolonged harvesting times (Fig. 2). Cyanidin content was 16-20 times higher than that of delphinidin under both transplanting and harvesting time in Hongjinju. This variety pigmented by red color contained only two kinds of anthocyanins, delphinidin and cyanidin except for pelargonidin. It is known that dihydroflavonol 4-reductase (DFR) is a key enzyme in pelargonidin biosynthesis and color expression of husk, leaf, and flower (Nakamura et al., 2010). Expression of genes for DFR, which catalyzes dihydrokaempferol to leucopelargonidin in petunia mutants that are deficient in ${ }^{2} 3^{\prime} \mathrm{H}$ and $\mathrm{F}^{\prime} 5^{\prime} \mathrm{H}$,

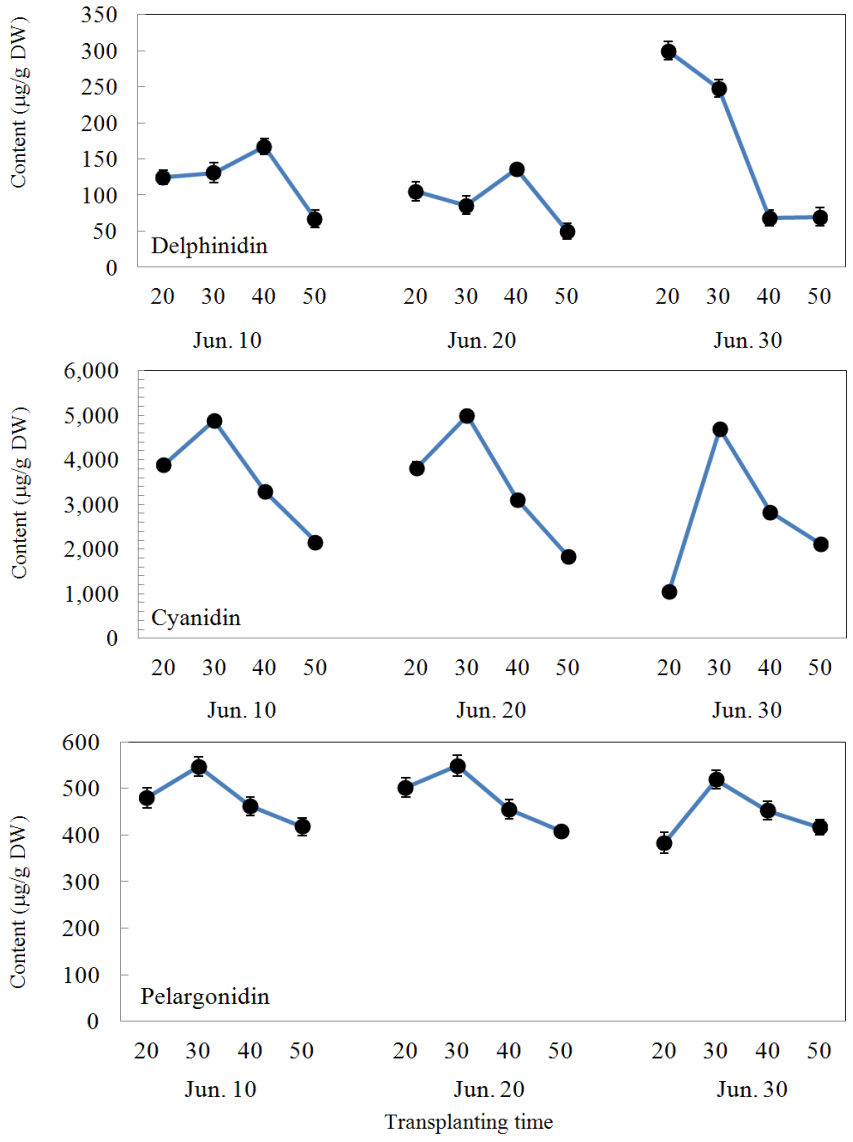

Fig. 3. Changes of delphinidin, cyanidin, and pelargonidin as affected by different transplanting and harvesting time in pigmented rice variety, Sintoheugmi. Vertical bar indicates means $\pm \operatorname{SE}(n=3)$.

results in pelargonidin production (Tanaka et al., 1995). Therefore it suggests that the genes for DFR biosynthesis may absent or deficient in Hongjinju during grain development. Unlike Hongjinju, Sintoheukmi showed that cyanidin content was the highest among analyzed pigments during seed development (Fig. 3). In change of delphinidin content, late transplanting time significantly increased delphinidin contents at 20 and 30 days after heading. Meanwhile, two anthocyanidins (cyanidin and pelargonidin) showed highest amounts only at 20 days after heading in all transplanting times.

Figure 4 presents the changes of anthocyanin pigments as affected by different transplanting time and harvesting time in Josaengheugchal. Two anthocyanins (cyanidin and pelargonidin) recorded highest contents at 20 days after heading in three transplanting times. Cyanidin content was also slightly increased with prolonged transplanting time.

Figure 5 shows changes of total anthocyanidin content as 

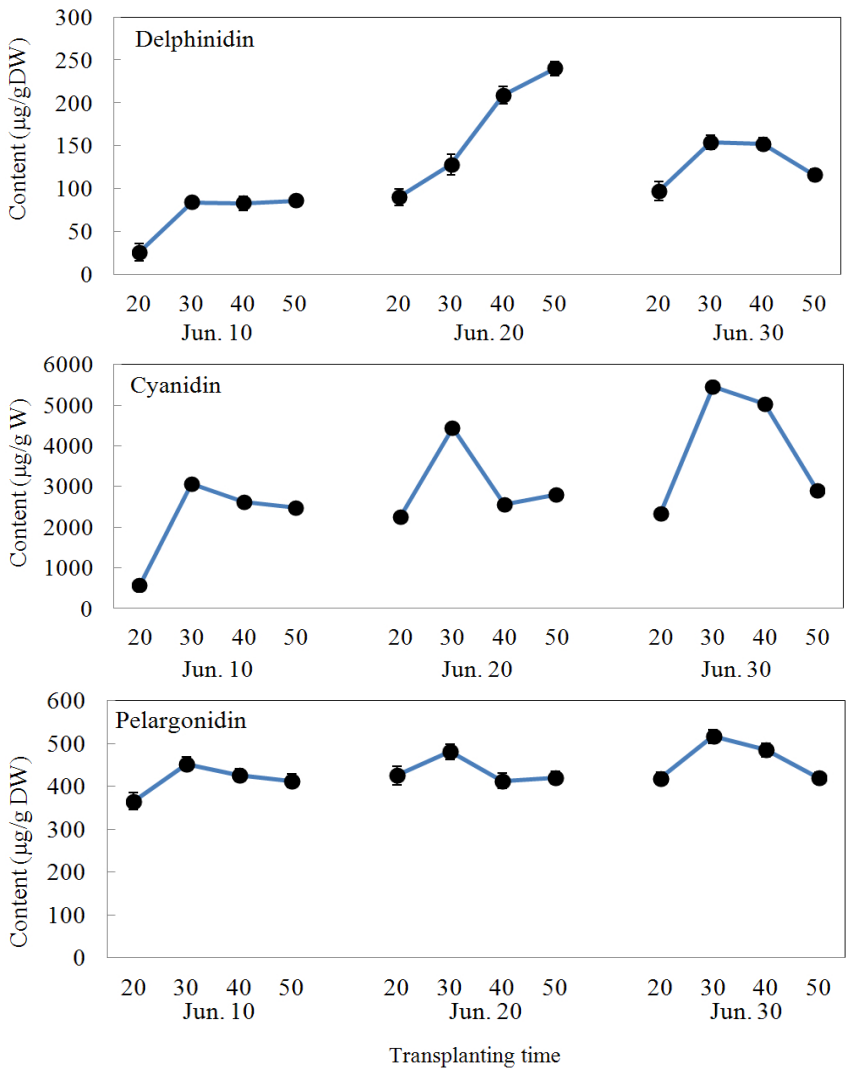

Fig. 4. Changes of delphinidin, cyanidin, and pelargonidin as affected by different transplanting and harvesting time in pigmented rice variety, Josaengheugchal.Vertical bar indicates means $\pm \operatorname{SE}(n=3)$.

affected by different transplanting time in three pigmented rice varieties. In Honginju, total anthocyanidin contents were slightly decreased with late transplanting and harvesting time. It showed that Sintoheukmi and Josaengheugchal recorded highest total anthocyanidin contents at 20 days after heading in all transplanting times. In particular, total anthocyanidin contents in Josaengheugchal were gradually increased with delaying transplanting times. Total anthocyanidin contents in Hongjinju were always lower than that of Sintoheukmi and Josaengheukchal. In Heugjinju and Heungnambyeo, pigment content especially cyanidin-3-glucoside $(\mathrm{C} 3 \mathrm{G})$ in brown rice is influenced by ambient temperature, and it varied by cultural environmental factors as well as variety (Chae et al., 2003). They reported that $\mathrm{C} 3 \mathrm{G}$ content at $18^{\circ} \mathrm{C}$ during seed ripening was lower. The $\mathrm{C} 3 \mathrm{G}$ content of Heuginju which was $1,837 \mathrm{mg} / 100 \mathrm{~g}$ brown rice at $24^{\circ} \mathrm{C}$ during seed ripening was higher than that of Heugnambyeo. The production of $\mathrm{C} 3 \mathrm{G}$ content at different ripening temperatures had a similar tendency

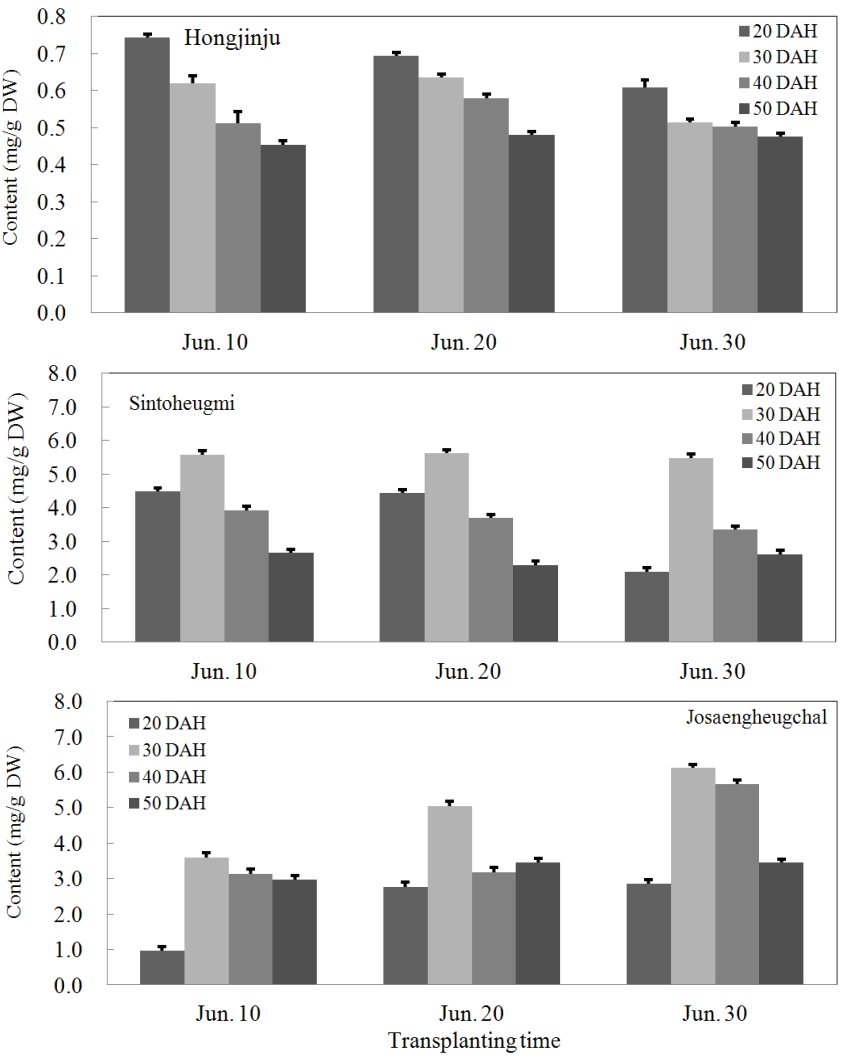

Fig. 5. Changes of total anthocyanidin pigment contents as affected by different transplanting and harvesting time in three pigmented rice varieties. Vertical bar indicates means \pm SE $(n=3)$.

to the C3G contents. In our present study, Hongjinju showed highest anthocyanidin content in 20 days after harvesting at 24.8, 24.9, and $23.1^{\circ} \mathrm{C}$ at transplanting time Jun. 10, Jun. 20 and Jun. 30, respectively. In particular, Josaengheugchal showed that lower ripening temperature produced higher anthocyanidin content at 30 days after harvesting time (Table 2).

Table 3 and Figure 6 show the color parameters $\left(\mathrm{L}^{*}, \mathrm{a}^{*}\right.$, and $b^{*}$ ) of three pigmented brown rices and grain color degree as affected by different planting and harvesting times, respectively. The $L^{*}$ values, which expresses the brightness, were in the range of 38.4 50.9, 17.0 22.7, and 17.0 26.2 in Hongjinju, Sintoheukmi, and Josaengheugchal, respectively. The $\mathrm{a}^{*}$ values, which expresses the redness positively and greenness negatively were in the range of 4.7 12.1, 5.2 6.8, and 5.2 7.9 in Hongjinju, Sintoheugmi, and Josaengheugchal, respectively. In addition, the $\mathrm{b}$ values, which expresses the yellowness positively and blueness negatively were in the range of 13.5 16.3, -0.1 -6.4, and $-1.5 \sim 6.9$ in Hongjinju, Sintoheugmi, 
Table 1. Heading time, mean and accumulative temperature as affected by different transplanting and harvesting time in three pigmented rice varieties, Hongjinju, Sintoheugmi, and Josaengheugchal.

\begin{tabular}{|c|c|c|c|c|c|}
\hline Varieties & $\begin{array}{l}\text { Transplanting time } \\
\text { (date) }\end{array}$ & $\begin{array}{l}\text { Harvesting time } \\
\left(\mathrm{DAH}^{\jmath}\right)\end{array}$ & $\begin{array}{l}\text { Heading time } \\
\text { (date) }\end{array}$ & $\begin{array}{l}\text { Mean temp. }{ }^{\dagger} \\
\left({ }^{\circ} \mathrm{C}\right)\end{array}$ & $\begin{array}{c}\text { Accumulative temp. } \\
\left({ }^{\circ} \mathrm{C}\right)\end{array}$ \\
\hline \multirow[t]{12}{*}{ Hongjinju } & Jun.10 & 20 & Aug. 16 & 24.8 & 496 \\
\hline & & 30 & & 24.7 & 742 \\
\hline & & 40 & & 24.0 & 958 \\
\hline & & 50 & & 22.7 & 1,137 \\
\hline & Jun.20 & 20 & Aug. 23 & 24.9 & 498 \\
\hline & & 30 & & 24.5 & 734 \\
\hline & & 40 & & 23.2 & 928 \\
\hline & & 50 & & 22.0 & 1,099 \\
\hline & Jun.30 & 20 & Aug. 28 & 23.1 & 462 \\
\hline & & 30 & & 21.3 & 640 \\
\hline & & 40 & & 20.5 & 818 \\
\hline & & 50 & & 19.5 & 973 \\
\hline \multirow{12}{*}{ Sintoheugmi } & Jun.10 & 20 & Aug. 7 & 25.6 & 512 \\
\hline & & 30 & & 25.8 & 774 \\
\hline & & 40 & & 25.6 & 1,023 \\
\hline & & 50 & & 24.6 & 1,231 \\
\hline & Jun.20 & 20 & Aug. 15 & 25.1 & 502 \\
\hline & & 30 & & 24.8 & 744 \\
\hline & & 40 & & 24.2 & 966 \\
\hline & & 50 & & 23.5 & 1,174 \\
\hline & Jun.30 & 20 & Aug. 25 & 25.1 & 502 \\
\hline & & 30 & & 24.4 & 731 \\
\hline & & 40 & & 22.9 & 917 \\
\hline & & 50 & & 21.9 & 1,096 \\
\hline \multirow[t]{12}{*}{ Josaengheugchal } & Jun. 10 & 20 & Aug. 28 & 25.6 & 512 \\
\hline & & 30 & & 23.8 & 714 \\
\hline & & 40 & & 22.2 & 887 \\
\hline & & 50 & & 21.3 & 1,063 \\
\hline & Jun.20 & 20 & Aug. 31 & 24.7 & 493 \\
\hline & & 30 & & 23.0 & 690 \\
\hline & & 40 & & 21.5 & 859 \\
\hline & & 50 & & 20.5 & 1,025 \\
\hline & Jun.30 & 20 & Sep. 1 & 24.2 & 484 \\
\hline & & 30 & & 22.6 & 678 \\
\hline & & 40 & & 21.3 & 850 \\
\hline & & 50 & & 20.3 & 1,014 \\
\hline
\end{tabular}

$\dagger,{ }^{\ddagger}$ Mean and accumulative temperatures were from heading time from harvesting time, respectively.

'Days after heading.

and Josaengheugchal, respectively.

In Hongjinju, $\mathrm{L}^{*}$ values were significantly decreased with late transplanting and harvesting times. $a^{*}$ value was slightly increased and $\mathrm{b}$ value was reversely decreased by late transplanting and harvesting times. Consequently, it showed more red-brown colors. In Sintoheugmi and Josaengheugchal, a* value was commonly slightly decreased by late transplanting and harvesting times. It can be noticed that $a^{*}$ and $b^{*}$ values in Sintoheugmi and Josaengheugchal varied more than those in Hongjinju. It was reported that the differences in the grain color of these 
Table 2. Changes of color value as affected by different transplanting and harvesting time in three pigmented rice varieties, Hongjinju, Sintoheugmi, and Josaengheugchal.

\begin{tabular}{|c|c|c|c|c|c|}
\hline \multirow{2}{*}{ Varieties } & \multirow{2}{*}{$\begin{array}{l}\text { Transplanting time } \\
\text { (date) }\end{array}$} & \multirow{2}{*}{$\begin{array}{l}\text { Harvesting time } \\
\quad\left(\mathrm{DAH}^{\dagger}\right)\end{array}$} & \multicolumn{3}{|c|}{ Hulled rice color } \\
\hline & & & $\mathrm{L}^{*}$ & $a^{*}$ & $b^{*}$ \\
\hline \multirow[t]{12}{*}{ Hongjinju } & \multirow[t]{4}{*}{ Jun. 10} & 20 & $50.9 \mathrm{a}$ & $4.8 \mathrm{f}$ & $15.1 \mathrm{c}$ \\
\hline & & 30 & $43.7 \mathrm{~d}$ & $9.9 \mathrm{c}$ & $14.9 \mathrm{c}$ \\
\hline & & 40 & $42.5 \mathrm{e}$ & $10.9 \mathrm{c}$ & $15.7 \mathrm{~b}$ \\
\hline & & 50 & $40.3 \mathrm{f}$ & $11.3 \mathrm{~b}$ & $15.9 \mathrm{~b}$ \\
\hline & \multirow[t]{4}{*}{ Jun. 20} & 20 & $48.5 \mathrm{~b}$ & $5.5 \mathrm{e}$ & $14.0 \mathrm{~d}$ \\
\hline & & 30 & $45.7 \mathrm{c}$ & $10.1 \mathrm{c}$ & $16.3 b$ \\
\hline & & 40 & $42.8 \mathrm{e}$ & $10.3 \mathrm{c}$ & $14.6 \mathrm{c}$ \\
\hline & & 50 & $38.4 \mathrm{~g}$ & $12.1 \mathrm{a}$ & $13.5 \mathrm{e}$ \\
\hline & \multirow[t]{4}{*}{ Jun. 30} & 20 & $50.7 \mathrm{a}$ & $4.7 \mathrm{f}$ & $16.1 \mathrm{~b}$ \\
\hline & & 30 & $47.8 \mathrm{~b}$ & $9.0 \mathrm{~d}$ & $16.9 \mathrm{a}$ \\
\hline & & 40 & $41.5 \mathrm{e}$ & $10.5 \mathrm{c}$ & $13.7 \mathrm{~d}$ \\
\hline & & 50 & $38.7 \mathrm{~g}$ & $11.4 \mathrm{~b}$ & $15.1 \mathrm{c}$ \\
\hline \multirow[t]{12}{*}{ Sintoheugmi } & \multirow[t]{4}{*}{ Jun. 10} & 20 & $18.0 \mathrm{~cd}$ & $6.3 \mathrm{~b}$ & $-5.6 \mathrm{~b}$ \\
\hline & & 30 & $17.0 \mathrm{e}$ & $6.5 \mathrm{~b}$ & $-6.2 \mathrm{a}$ \\
\hline & & 40 & $17.1 \mathrm{e}$ & $5.5 \mathrm{~cd}$ & $-6.4 \mathrm{a}$ \\
\hline & & 50 & $18.6 \mathrm{~d}$ & $5.6 \mathrm{~cd}$ & $-5.4 \mathrm{~b}$ \\
\hline & \multirow[t]{4}{*}{ Jun. 20} & 20 & $18.2 \mathrm{~cd}$ & $6.4 \mathrm{~b}$ & $-5.6 \mathrm{~b}$ \\
\hline & & 30 & $17.7 \mathrm{~d}$ & $6.1 \mathrm{c}$ & $-5.9 a$ \\
\hline & & 40 & $17.1 \mathrm{e}$ & $5.4 \mathrm{~d}$ & $-6.3 a$ \\
\hline & & 50 & $18.0 \mathrm{~cd}$ & $5.7 \mathrm{~cd}$ & $-5.6 \mathrm{~b}$ \\
\hline & \multirow[t]{4}{*}{ Jun. 30} & 20 & $22.7 \mathrm{a}$ & $6.8 \mathrm{a}$ & $-0.1 \mathrm{c}$ \\
\hline & & 30 & $17.8 \mathrm{~d}$ & $5.9 \mathrm{c}$ & $-5.8 \mathrm{a}$ \\
\hline & & 40 & $17.7 \mathrm{~d}$ & $5.5 \mathrm{~cd}$ & $-6.2 a$ \\
\hline & & 50 & $19.4 \mathrm{~b}$ & $5.2 \mathrm{~d}$ & $-5.5 \mathrm{~b}$ \\
\hline \multirow{12}{*}{ Josaengheugchal } & \multirow[t]{4}{*}{ Jun. 10} & 20 & $26.2 \mathrm{a}$ & $7.9 \mathrm{a}$ & $2.6 \mathrm{~d}$ \\
\hline & & 30 & $18.8 \mathrm{c}$ & $5.7 \mathrm{c}$ & $-1.5 \mathrm{e}$ \\
\hline & & 40 & $16.7 \mathrm{~d}$ & $5.8 \mathrm{c}$ & $-6.9 \mathrm{a}$ \\
\hline & & 50 & $17.6 \mathrm{~d}$ & $5.6 \mathrm{~cd}$ & $-6.2 \mathrm{a}$ \\
\hline & \multirow[t]{4}{*}{ Jun. 20} & 20 & $22.6 \mathrm{~b}$ & $6.0 \mathrm{c}$ & $-3.6 c$ \\
\hline & & 30 & $17.3 \mathrm{e}$ & $5.7 \mathrm{c}$ & $-6.4 a$ \\
\hline & & 40 & $17.6 \mathrm{~d}$ & $5.4 \mathrm{c}$ & $-6.4 a$ \\
\hline & & 50 & $17.9 \mathrm{~d}$ & $5.4 \mathrm{c}$ & $-6.1 \mathrm{a}$ \\
\hline & \multirow[t]{4}{*}{ Jun. 30} & 20 & $19.2 \mathrm{c}$ & $6.9 \mathrm{~b}$ & $-4.3 b$ \\
\hline & & 30 & $17.0 \mathrm{e}$ & $5.6 \mathrm{~cd}$ & $-6.6 a$ \\
\hline & & 40 & $17.2 \mathrm{e}$ & $5.2 \mathrm{~d}$ & $-6.6 a$ \\
\hline & & 50 & $17.2 \mathrm{e}$ & $5.2 \mathrm{~d}$ & $-6.5 \mathrm{a}$ \\
\hline
\end{tabular}

${ }^{\dagger} \mathrm{DAH}$ : days after heading.

pigmented rices could depend on the form of anthocyanins and rice genotypes (Yawaido et al., 2007; Escribano-Bailon et al., 2004).

Figure 7 shows changes of brown rice yields as affected by different transplanting and harvesting times in three pigmented rice varieties. The results revealed that highest brown rice yield in Hongjinju was produced when it was harvested by 30 days after heading at transplanting time Jun 20. Brown rice yield in Sintoheugmi showed the greatest decease among these pigmented rice varieties. In Josaengheugchal, early harvesting before maturity showed lower brown rice yield and late harvesting in the each transplanting times resulted in highest 


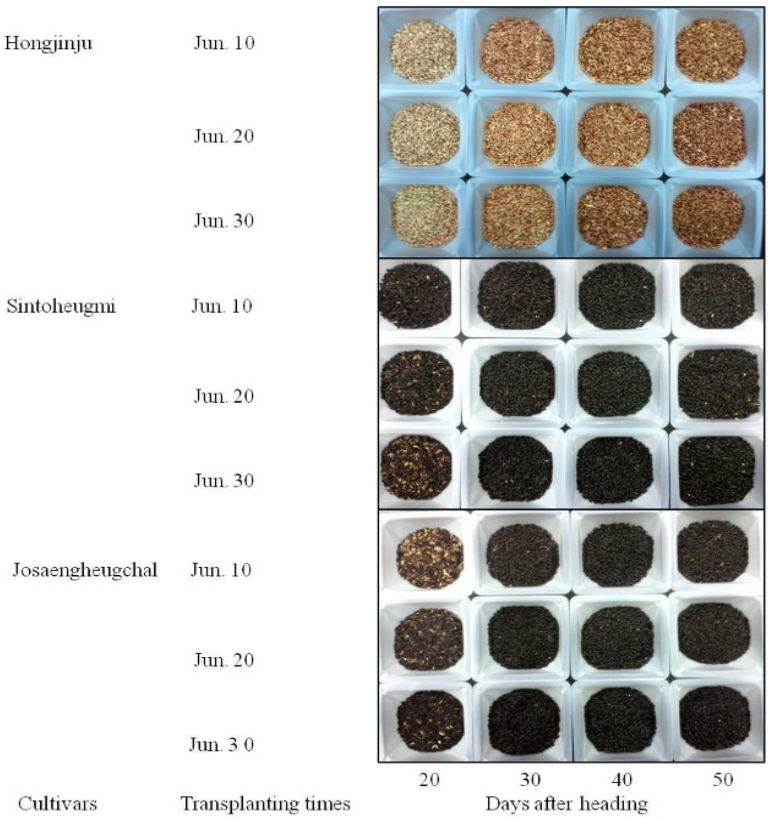

Fig. 6. Grain color degree in three pigmented rice varieties as affected by different transplanting and harvesting times.
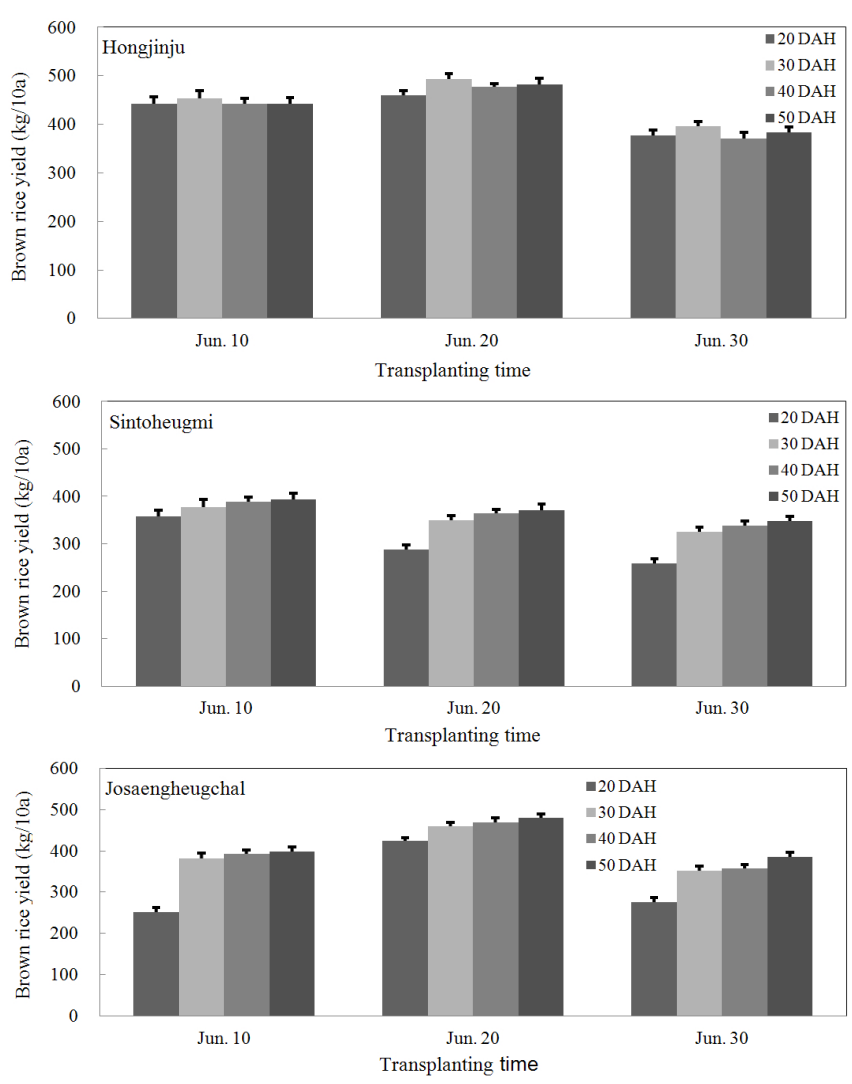

Fig. 7. Brown rice yield as affected by different transplanting and harvesting time in three rice varieties, Hongjinju, Sintoheugmi, and Josaengheugchal. Vertical bar indicates means $\pm \operatorname{SE}(n=3)$. brown rice yield. Among these transplanting times, the transplanting time at Jun. 20 showed highest brown rice yield in Josaengheugchal.

\section{REFERENCES}

Abdel-Aal, E. SM. and P. Hucl. 1999. A rapid method for quantifying total anthocyanins in blue aleurone and purple pericarp wheats. Cereal Chem. $76: 350-354$.

Chae, J. C., D. J. Lee, D. K. Jun, S. N. Ryu, and J. C. Shin. 2003. Effect of ripening temperature on content of anthocyanin pigment cyanidin-3-glucoside and oryzanol in rice varieties. Proceedings of the Korean Society of Crop Science Conference. The Korean Soc. of Crop Sci. 226-227.

Choi, S. W., W. W. Kang, and T. Osawa. 1994. Isolation and identification of anthocyanin pigments in black rice. Foods and Biotech.3 : 131-136.

Choung, M. G., I. Y. Baek, S. T. Kang, W. Y. Han, D. C. Shin, H. P. Moon, and K. H. Kang. 2001. Isolation and determination of anthocyanins in seed coats of black soybean (Glycine max (L.) Merr.). J. Agric. Food Chem. 2001. 49 : 5848-51.

Chung, I. M., K. H. Kim, J. K. Ahn, and J. C. Chae. 2003. Development of rice production technique with high antioxdative activity and bioactive compounds. Korean Ministry of Agriculture and Forestry, Agricultural R\&D research report, 35-80.

Escribano-Bailn, M. T., C. Santos-Buelga, and C. Rivas-Gonzalo. 2004. Anthocyanins in cereals. J. Chromatogr. A. 1054(1-2) : 129-141.

Francis, F. J. 2000. Anthocyanins and betalains composition : composition and applications. Cereal Foods World 45 : 208-213.

Hu, C., J. Zawistowski, W. Ling, and D. D. Kitts. 2003. Black Rice (Oryza sativa L. indica) pigmented Fraction Suppresses both Reactive Oxygen Species and Nitric Oxide in Chemical and Biological Model Systems. J. Agric. \& Food Chem. (51) : 5271-5277.

Hyun, J. W. and H. S. Chung. 2004. Cyanidin and malvidin from Oryza sativa cv. Heugjinjubyeo mediate cytotoxicity against human monocytic leukemia cells by arrest of G2/M phase and induction of apoptosis. J. Agric. Food Chem. 52 : 2213-2217.

Iqbal, S., M. I. Bhanger, and F. Anwar. 2005. Antioxidant properties and components of some commercially available varieties of rice bran in Pakistan. Food Chem. 93 (2) : 265-272.

Lamberts, L., E. D. Bie, G. E. Vandeputte, W. S. Veraverbeke, V. Derycke, W. D. Man, and J. A. Delcour. 2007. Effect of milling on color and nutritional properties of rice. Food Chem. 100 (4) : 1496-1503.

Nakamura, N., F. M. Masako, F. Yuko, I. Kanaki, S. Kenichi, S. Hideyuki, O. Koei, and S. Daisuke. 2010. Generation of pink flower varieties from blue Torenia hybrida by redirecting the flavonoids biosynthetic pathway from delphinidin to pelargonidin. Plant Biotech. 27 : 375-383. 
Mazza, G. and L. Gao. 2005. Blue and purple grains. In : Abdel-Aal E-SM \& Peter PJ (Eds.), Specialty Grains for Food and Feed, p.45-67. American Association of Cereal Chemists. St. Paul. USA.

Moreno, Y. S., G. S. Sánchez, D. R. Hernández, and N. R. Lobato. 2005. Characterization of anthocyanin extracts from maize kernels. J. Chromatogr. Sci. 43 : 483-487.

Nam, S. H., S. P. Choi, M. Y. Kang, H. J. Koh, N. Kozukue, and M. Friedman. 2006. Antioxidative activities of bran from twenty one pigmented rice cultivars. Food Chem. 94 : 613-620.

Philpott, M., K. S. Gould, C. Lim, and L. R. Ferguson. 2006. In situ and in vitro antioxidant activity of sweetpotato anthocyanins. J. Agric. Food Chem. 54 : 1710-1715.

Ryu, S. N., S. Z. Park, and C. T. Ho. 1998. High performance liquid chromatographic determination of anthocyanin pigments in some varieties of black rice. J. Food and Drug Anal. 6 : 729-736.

Tanaka, Y., Y. Fukui, M. Fukuchi-Mizutani, T. A. Holton, E. Higgins, and T. Kusumi. 1995. Molecular cloning and characterization of Rosa hybrida dihydroflavonol 4-reductase. Plant Cell Physiol. 144 : 846-856.
Tsuda, T., F. Horio, and T. Osawa. 2002. Cyanidin 3-O-ß-glucoside suppresses nitric oxide production during a zymosan treatment in rats. J. Nutr. Sci. Vitaminol. 48 : 305-310.

Yawadio, R., S. Tanimori, and N. Morita. 2007. Identification of phenolic compounds isolated from pigmented rices and their aldose reductase inhibitory activities. Food Chem. 101(4) : 1616-1625.

Yoon, H. H., Y. S. Paik, J. B. Kim, and T. R. Hahn. 1995. Identification of anthocyanidins from Korean pigmented rice. Agric. Chem. and Biotech. 38 : 581-583.

Yoshinaga, K. 1986. Liquor with pigments of red rice. J. Brewing Society of Japan $81: 337-342$.

Zhao, C., M. M. Giusti, M. Malik, M. P. Moyer, and B. A. Magnuson. 2004. Effects of commercial anthocyanin-rich extracts on colonic cancer and nontumorigenic colonic cell growth. J. Agric. Food Chem. 52 : 6122-6128.

Zhang, M. W., B. J. Guo, R. F. Zhang, J. W. Chi, Z. C. Wei, Z. H. Xu, Y. Zhang, and X. J. Tang. 2006. Separation, purification and identification of antioxidant compositions in black rice. Agricultural Science in China 5 (6) : 431-440. 